\title{
Having Lost for Fear of Losing: Culture, Individual Interests and the Negative Spiral of the Italian Case
}

\author{
Antonio Putini \\ Department of Political Science, Sapienza University, Italy
}

Copyright $(\mathcal{C} 2015$ by authors, all rights reserved. Authors agree that this article remains permanently open access under the terms of the Creative Commons Attribution License 4.0 International License

\begin{abstract}
The present contribution stands as a wider sociological reflection of some empirical evidence resulting from a national research project entitled "Federalism, Local Autonomy and Quality of Democracy". In an attempt to understand the reasons for the substantial halt of the federal reform process in Italy, analysis of content of 60 interviews given by privileged witnesses of the administrative and local political system emphasized some cultural traits which played a seminal role. Above all, it has been detect the persistence of a ruling-classes political culture geared toward a "private" or group-oriented dimension of interest more than in accordance with public and collective aims, which creates a network of relationships between politics, society and the economy. This network is oriented to the defence of what has been achieved thanks to familistic (or neo-feudalist) mechanisms of interaction. By looking at the picture that emerges within a wider constructivist theoretical framework, it is possible to understand the Italian lack of engagement towards the bandwagon formed by countries that have managed to gain an advantage through the phenomena of globalization in terms of growth, competitiveness, development and democratization of decision-making processes in their political systems (by implementing, for example, inclusive decision-making practices supported by the use of new technologies of information and communication). The aim of the contribution is therefore a reflection on the Italian identity and political culture and their weight in shifting the impact of globalization from a potential added value for both national and local development to the virtual present loss of competitiveness of the whole system.
\end{abstract}

Keywords Culture, Political Culture, National Identities, Élites, Globalization, Social Ties

\section{Introduction}

Identity and stereotype represent modes of perception of the 'self' and the 'other', whose construction processes at collective level substantially reflect the individual level: each individual "looks" to him/herself and to others through abstractions, symbols and generalisations arising from the interaction between person and community, enabled thanks to the process of socialisation [1]. Similarly, groups and communities form their specific 'views' of themselves and the others by using symbols, myths, 'building' traditions [2] and 'labels' that allow to 'identify characteristics and behavioral expectations of the others in a concise and immediate way' [3].

According to Santambrogio [4] the social representation corresponds to an 'unconscious knowledge', with which the individual comes into contact, through his belonging to a group, so that 'he sees the world through the eyes of the group to which he belongs, thinking that is his way to see and the right way to see it'.

Starting from these, we can then define the culture of a given society as "the intellectual and material heritage (...) made of values, norms, definitions, languages, symbols, signs, behavioural patterns, mental and body techniques, having cognitive, affective, evaluative, expressive, regulative and manipulative function" [5 p.186].

The present article grounds on the hypothesis that the form and content of action of individuals and, more in general, of groups - rather than the structural characteristics of a social group, linked to the concept of class, or the systemic features, its material resources or its 'political and institutional architecture' - can shape, internally, structures and systems, and, externally, the ability to take initiative or to respond to a stimulus, such as a technological innovation, a change in the production system or a financial and economic crisis.

There are reasons that call into question the sphere of collective identity and substantiate, at a collective level, in cultural traits that mould and shape the social behaviour of entire groups of professionals.

Above all, it is about cultural features along the slow process of historical change, which meet the wave of the individualisation process, resulting, in the Italian case, strengthened but in a negative sense. 
'Local' features of social and cultural development overlap the deep global currents and the dichotomous effects of the individualisation process, and they may in fact determine conditions for or against change, able to 'hold' and accompany external solicitations, or rather be overwhelmed and resulting in an acceleration of ties and social fabric attrition process.

Obviously we do not intend to say that 'all' the causes of the Italian stagnation are to be attributed to the cultural dimension, but rather that, given the global crisis, the effects are magnified when they meet specific cultures and collective attitudes which affect the social action.

Thus, our hypothesis is based on a constructivist approach [6] and it argues that the recession that has hit the Italian system for at least 4 years is only partially linked to cyclical factors (the global crisis), or structural macro-economic issues (the public debt, the burden of interest on the debt, the crisis of public finance, the lack of investments in innovation and production).

The underlying reasons, on the contrary, arise from cultural traits that affect, in order, the political class, the business class, and the 'social' combination of citizens and civil society. These traits influence the political and social action of individuals belonging to the above mentioned groups, so to produce an overall output characterized by a systemic fragmentation and weakness that exposes to greater risks of adverse impacts, associated with any change, not only in market but also in political conditions.

The cultural traits of the political class, of the business class and of the workers have therefore established, over the time, a 'systemic disadvantage', a complex web of dysfunctional relationships related to the research of inter-group benefits, if not even individual benefits.

In order to obtain such a result it is not necessary that a lack of publicness and civicness pervades the entire society.

It only needs its dominance in the cores from which radiates the political and economic power, combined with a 'passive' acceptance, deriving in part from the same quest for some advantage, and in part by the 'traditional' deference citizenry shows towards the authority. This statement is well known within social science since Lijphart studies concerning the Dutch society, the democratic regimes and the role played by their political élites $[7,8]$.

Moreover, we know, according to Crozier [9] for instance, that the bureaucratic system of a Nation 'reflects' the 'cultural' characteristics of its inhabitants: thus, for example, the isolation of groups, the scarcity of informal relationships, or the extensive use of impersonal rules - highlighted in the case studies examined by the French sociologist - are explained not so much as features of a 'predominant' bureaucratic system resulting from the process of rationalisation (the Weberian ideal type), but by virtue of 'cultural traits that are rather rooted in France' (p. 240) [9].

The French isolation in terms of interactions, the lack of 'cooperative spirit', the closure towards upward social mobility, are the elements described not only by Crozier, but also in Tocqueville in regard to the French society of the nineteenth century, and in Goblot [10], who, in the early decades of the twentieth century, showed the 'techniques' in which the upper layers could 'isolate' and 'seal', in respect to the attempts of advancing of the lower layers.

These same traits have been enclosed in the 'French stereotype' described by Arianna Montanari [1], who resorts to the transactional analysis of Berne to identify in the type 'Me + /You - ' the essential characteristic of these people collective identity, while, for the Italian case, this type has to be identified by the scheme 'Me - /You +'.

The proposed key to understanding the Italian case is based, therefore, on a specific process of fragmentation and on a lack of public spirit and sense of belonging to a common and wider social group (i.e. the nation) that characterises the historical evolution, the "construction' and "reproduction" of the Italian identity. Evidences of this process has come by the contents of the interviews administered in our case study regarding the federal reform, which underline a multi-dimensional conflict among political actors at different level of administration. Further and more general evidences, which strengthen our case study results, can be found by looking at other symbols of Italian culture and identity, such as literary and movie production.

We deal with a social fragmentation and a political pulverisation of the collective interests which were born to maintain particular interests and that lead to a 'paralysis', and, in the long run, to defeating a whole system determined by the fear of losing what has been acquired by parts of it.

\section{The Italian Federal Reform: From an Institutional Renewal to a Missed Opportunity}

During the year 2013, the chair of political sociology at Sapienza University of Rome, together with 4 other Italian Universities, led the survey for a research project aimed to restore the possible answers to the impasse in the Italian federal reform process.

The survey started with the analysis of documentary sources produced by the institutions involved in the reform (parliamentary records, files produced by technical committees, scientific production of lawyers, sociologists and political scientists), and continued through 60 in-depth interviews aimed at the players of the same process: local representatives, directors and regional administrative staff.

The collected interviews and documents constitute the material from which we mined the considerations proposed in this article.

The normative aim of the federal reform was, on an administrative level, to 'modernise' the system by giving empirical translation of principles such as subsidiarity, simplification, administrative transparency, and the optimisation of the management of public resources, through the decentralisation of decision-making and service centres.

On a political level, this aspired to reconnect politics and administration with the citizen, to recover, through this and 
other legislative and political interventions, a frayed relationship of trust, that only a few years earlier had received yet another blow by the events of 'tangentopoli' (Bribesville). Above all, the reform aimed to remove the spectre of potential secessionist phenomenon, played by the populist party "La Lega", which began to make inroads not only in the centre-right constituency, but also in the left electorate.

To summarize, federal reform was the tool for both a democratization process and a national consolidation attempt.

The redefinition of the spheres of competence has proven extremely complex and, above all, a long-gestation (now 14 years). It has been so difficult as to make some people talk of the 'great unaccomplished' referring to the reform, or of a 'crooked tree' with respect to the process [11]. As at today, not only is the process unfinished, but further reform proposals have been added, such as the Senate Reform and some others.

Behind this long-gestation process we can find mutual political vetoes, inter-institutional and intra-party conflicts as well as strategic actions which can be read as examples of an institutional and collective-oriented process stopped by groups attempting to defend particular or specific interests.

"To realize in a concrete meaning a federal reform means to have an idea of the Nation that, unfortunately, those who took part in this process during the last ten years did never possess...on the contrary, they looked only at their interests, above all electoral ones! As they were only local interests, they produced a crossroad of contradictions and paradox!" Administrative Director, Umbria 1

In fact, according to the opinion of the interviewers the Italian federal reform has essentially been a missed opportunity, a process born out of a compromise of strategic and political nature; a "jumble" of rules and revisions, amongst the effects of which there has been a substantial indeterminacy of the roles pertaining to state on the one hand, and to local authorities on the other. This compromise shows a substantial lack of a "wide-ranging political vision" which could have ensured a better connection between national and local legislative and administrative duties.

"While in the previous regionalism system there was a strong tie between democracy and development or between democracy, State reform and quality of the development, the actual Federal Reform comes from an illusion: that is, the illusion of the left-wing party to give an immediate answer to the Northern question ... the previous institutional order, that is regionalism, has been the result of an in-depth reflection concerning the Italian economic and institutional path, the present institutional arrangement has missed this seminal argument"

Pol.Umbria3

Thus, what seems to lack since the beginning of this reform is a deliberative moment among the different political forces, that, in terms of political values, can be explained as the decline of the "constitutional spirit" which had guided the previous four decades of Italian political life. In fact, despite the substantial differences between the Christian Democracy (DC) and the Italian Communist Party (PCI), a general consensus on the most important norms - and about their possible reform - has always existed. Specific studies conducted by Giovanni Sartori during the 1960s, show that $74 \%$ of the laws overall approved has been voted by the Communist Party during the first four legislatures of the Second World War republican period.

On the contrary, the own modalities that led to the first federal reformist step, that is the Constitutional Law which has emended the norms concerning central and local legislative powers, represents a first indicator of a political change derived from a cultural "shift": from a consociational model, which, despite the conflicts among political subjects, accepts " a minimum of fundamentals", to a centrifugal scheme based on the sole will of the relative majority:

"That Reform, adopted at the very end of the legislature, with a restricted majority, has produced a constitutional jerk in our republican tradition that has been used as a "model" for further jerks, like the one carried out by Berlusconi concerning the electoral law, in 2005. That precedent has a negative effect whose injuries we are still paying nowadays. Discontinuing with the precedent Constitutional reform approval practices is been a great damage!"

Pol.Lazio2

In this 'strategic' dimension relating to the conduct of the political actors of the reform, the contrast between regions and state - after the new phase of "centralization" and the consequent 'hold' of funds started in 2012 - also assumes an instrumental connotation: some local political elites, for example, justify their opposition to financial cuts in the form of needs for services and pursuit of virtuous principles of good administration.

This justification masks the need to maintain position and revenues through the ability to manage the consensus network, useful to their self-perpetuation.

The hypothesis, deriving from the content analysis of a witness from the Umbria Region, is confirmed in other interviews, including that of a director from the Lazio Region, who admits that the costs of the Regional Council leavened by about $700 \%$ (from 2 to less than 14 million euro) in two years - are in fact the ploy used by the Governor (Renata Polverini) to 'reward' the counsellors and maintain, in this way, the appearance of political cohesion:

'That kind of funding, given to the groups, was the way in which Polverini paid his majority, and without that tool, probably, the majority would have dissolved two years before: this is the point that is not discussed enough!'

Pol. Lazio1

Upstream of the distorting effects produced by the reform of Title $\mathrm{V}$, the absence of control mechanisms on regional spending and, above all, on responsibility (administrative and political) at the head of cost centres have then acted upon. 
Not surprisingly, the control function has found a louder and louder supplementary role, over the past 10 years, in the Constitutional Court (called to settle disputes between State and Regions in terms of concurrent legislation, and litigations increased from 25 in 2000 to 141 in 2010) and the Court of Auditors, required in the increasingly complex task of local governments budgets verification [11].

The loss of political accountability and the subsidiary role played by both the Constitutional Court and the Court of Auditors, represent another trait of the changing political attitudes: the increase in power and availability of resources in the hands of regional agents have joined the lack of control 'from above' and of local accountability tools. For this reason 20 micro-systems were born, where local political elites gained more autonomy (and thus power) compared to the national leadership, exercising and reinforcing it through a 'tipping policy':

"Since you put an élite at the government of a region, it is obvious that this group will try to be reconfirmed. From the moment that the élite has this political problem it will spend all the instrument it possesses...Italian regions, through a wide political and financial autonomy, have a lot of resources...think about public hiring...I think you understand what I mean!"

Pol. Umbria 2

Other examples of fragmentation and conflict that arose in defence of special interests involve the political parties. The analysis of interviews and documentary sources has highlighted a rift that is not 'horizontal' and exogenous, i.e. between the political organisation and the society, but rather has a 'vertical' character and is endogenous, i.e. relating to internal relations in political parties.

Local politics have been, therefore, the cumulative effect of personalisation (due to electoral reforms and the changing balance in the relations between the County President, Council and the Councillors occurred with L. C. 1/99) and the increase in legislative, administrative and spending functions, without, we repeat, a proper provision for control tools and accountability.

Regions have therefore become 'autonomous territories' even in the political-party system, for which:

'You have a weak political party that chooses, or rather, is to take the road - not even of notability, but with a more modern expression of a 'franchising party'- where there is a unwritten agreement between a national level, which sees things on a high scale, and a schizophrenia of a local level, which cannot tolerate, let's say, the annoyance and interference from what was once the organised political entity, that is the political party'.

\section{Pol.Lazio 1}

The presence of this 'gap' between centre and periphery, coupled with the autonomy of the latter, crosses and exceeds the sociological phenomenon described as 'self-perpetuation' of organisations.

On one side, we are witnessing phenomena such as the dubious unconsciousness - or should we say the clear connivance - which came out in the Lazio Region from statements of non-involvement from leaders and members of opposing groups, who were sitting on the benches of the Regional Council when scandals exploded in reference to the use of public funds. This connivance encourages deletion of the last control tool left as safeguard of the virtuous use of local authorities expenditure: the local political opposition.

On the other side, more than witnessing an element of self-perpetuation in organisational terms (i.e. party), these episodes will show an excess in favour of the conservative principles 'ad personam', which aimed to ensure the permanence of individuals, together with their 'followers' and their relationship networks and local interests.

The case of federal reform in Italy shows a double face, and a the same "double ethic" mentioned by Montanari in her studies concerning Italian national identity [12 ]: on the one hand, we have the call to 'overturn' of all political components at any level of government (with the exception of the representatives from La Lega), that appealed to principles of social cohesion and solidarity - while not giving up the pursuit of a different 'institutional framework' - and wanted to pursue a principle of 'rapprochement' of politics and public administration to citizens and their needs.

A face, therefore, deeply steeped in rhetorical sense of morality, democracy and a spirit of service towards the community.

On the other hand, in the political and administrative 'backstage' away from the stage of television politics or of 'net-politics', we have records of Parliamentary Committees, documents submitted by various institutional stakeholders in the hearing process, reports of institutions such as the Constitutional Court or the Court of Auditors, which describe a profoundly different and much more complex reality, in whose plot - made more of mutual vetoes than shared tracks - lie at least two forms of conflict deriving from particular interests.

The first conflict has a territorial nature, with a first expression at a vertical level: so we have Local Authorities against Central Government. Along this axis lie the local authorities 'complaints' aimed at the demiurgic role of the Ministry of Economy and Finance, in regard to the decision-making procedures related to public finances, transfers and cuts to local resources. Also in this area are located the accusations of uncontrolled spending addressed to the management of the central government of the state.

The second expression has rather an horizontal axis: central and northern regions against southern regions. In this sense, we can read, for example, the responses of directors following the first SOSE results, related to the 'adjustment' and the consequential scenario deriving from the application of the essential Levels of performance.

There is then a second type of conflict or friction also detectable at both local and central levels: we speak of the struggle between majority and opposition, between political parties, or coalitions of parties or 'party coalitions' that occupy leadership positions, and their counterparts lined up 
on the minority banks.

Depending on the topic under discussion and the listening audience, the conflicting structures change, intertwine, overlap, to the point of pushing Cammelli [13] to talk about a 'gattopardesca' situation (that shows to adhere to the new order not to lose power and ancient privileges) in reference to the evolution of approval process of fiscal federalism.

At the centre of this 'multi-dimensional friction' there is a principle, or rather the pursuit of its circumvention, and a purpose: the principle is that of responsibility; the purpose, on the contrary, is the perpetuation of the obtained advantage position at individual or group level.

Reading the sequence of events in the light of this interpretive key, the statements of 'need for institutional reform in the federal sense to be performed at parliamentary level' - made by local political representatives, in the face of the real stalemate that exists in the representative offices appears understandable.

It is clear, then, as many local politicians do not find the cause of explosion of malpractice phenomena in the implementation of service decentralization following the federal reform, even if regions have, as a consequence of the reform, become 'financially irresponsible' cost centres - as noted by the Court of Accounts, so much to make it rise by $700 \%$ for costs related to Council functions, in cases such as the Lazio Region.

Moreover, Antonini [13] writes: 'The year was 2005, when, at a meeting on the hypothesis to predict a federal Senate starting from the second legislature after the one that was taking place, a senior senator objected to me: 'but if, from 2011, you reduce the Senate current powers, then what will I do?'. It's an emblematic episode of the resistance that is encountered when the reformers must reform themselves'.

We have gone from a period of twenty years (the one enclosed roughly between 1990 and 2009) of local political 'irresponsibility' in the mechanisms for the use of public resources spraying from the centre to the 'periphery', on the basis of historical cost criteria, to a phase of cost re-centralization, performed through the attempt to 'transfer' the responsibility for cuts to local level, made even more necessary by the fiscal and economic-financial crisis.

To all this, an intrinsic characteristic of the employment and development system (both regional and national) must then also be connected - the peculiarity of which directly involves citizens, as co-responsible for the impasse of such a structural reform.

In the presence of a political class that escapes the principle of responsibility, trying to 'transfer it' to a level of government other than the one occupied, by chasing votes and 'prebende' (benefits) [14], it binds in fact a part of society that accepts this dysfunction in exchange for economic and / or employment benefit [15], fostering in this way a vicious circle that undermines the effectiveness of any institutional reform aimed at a structural rationalization of expenditure, according to standard needs to be met, to guaranteed consistent performance and, especially, to equalization-oriented mechanisms inclined to social equity.
In conclusion, values and behavioral patterns emerged in this brief description concerning the Italian federal reform path, show an overall cultural frame which has lost its public dimension, its national aim in favour of local and personal interests.

If the cultural substratum which animates a constitutional reform is characterized by the lack of the political class accountability - combined with a widespread inclination to 'privately' manage public affairs - and a predisposition to the demand for excessive state aid from minute percentages of the population, it is almost a foregone conclusion that any attempt towards a federalist institutional reorganisation is intended to run aground, resulting in yet another case of general disadvantage arising from the fear of losing special benefits.

Opinions and facts harvested in this part of the article refers only to a specific case, but, as one privileged witness has told:

"The entire system lays on malfeasances and a wrong use of the public goods. Unfortunately this is an endemic feature of Italian democracy. A political and cultural phenomenon, which is turning into a distinctive trait of the entire country". Administrative Director, Lazio 3

Thus, what we're facing is a wider systemic cultural "attitude", describe by De Mucci [16] through a psychiatric metaphor, as a case of "dissociative democracy" that "seems to have built its foundation over a cultural issue that has been going for the last 20 years".

De Mucci talks about the tendency to develop a quarrelsome environment characterized by a mutual delegitimization not only between political parties, but also between institutional actors like the executive and the judicial powers, resulting in a scenario that closely resembles a paradoxical "civil cold war".

The next part of the article will explore this definition by giving some additional examples of political and social actions driven by a lack of civicness and public leanings.

\section{Particularism, Fragmentation and Illegality in the Italian Society}

By no chance Premier Renzi has based all his political communication efforts on symbolic and cultural components: from an attempt to establish a renewed civic spirit through a process of modernizing Italian administrative institutions and mechanisms and through the strong request to stay united, collaborate and engage in dialogue trained on the country's political, social and economic powers.

The key words are "reform", "streamline", "speed up" as well as the now celebrated binomial: junk and pave over.

Nor is it by chance that the only way to rise up out of the quicksand of the recession is to give the Italian system a shakeup with a balanced dose of pragmatism and optimism, leadership and a spirit of sharing, confidence and a dream. A right and proper dream of an Italian Renaissance as 
prescribed by the daily Le Monde.

So the sole solution is an attempt at a laborious reorganization working above all at the psychological and values levels and thus culturally.

But recourse to this set of symbols representing a political spirit can be justified only in light of the reality which must be profoundly changed, thus a sign of the opposite.

Though what the premier represents and calls for are written on a semantic slate dominated by optimism, a reformist spirit, innovation and a competitive stance, the explosive reality of the last two years revolves around the umpteenth scandals linking politics and business interests and provincial attitudes, singularism and anti-competition: we are referring to the Expo 2015 scandal, the MOSE - the Venice tide barrier project - case, and the last "Mafia Capitale" example of widespread corruption concerning local representatives, managers and civil society organizations in Rome.

Luca Zaia, the governor of the region caught up in the MOSE scandal surrounding the construction of the Venice tide barriers, commented, "Of course, we are evaluating an investigation framework which, if confirmed, opens onto a gloomy national picture. The Finance Police, senior magistrates, the secret services... there's enough for everybody... a dark chapter for the region because everybody comes away penalized, the managers, politics, business".

These cases of national and international relevance are flanked by tens of thousands of examples at the local and micro-local levels. Taken all together, aside from the monetary scale of the benefits derived from illegal activities, these episodes paint a tragic picture of the collective national image, of identity and the political and enterprise culture.

From the bankruptcy of the Azienda Ospedaliera San Raffaele Hospital in Milan, which literally squandered more than a billion euro with the involvement of public and private managers, wheeler-dealer intermediaries and regional managers, politicians and secretaries on to the more recent case of the abandoned mattresses in Rome where worn-out mattresses were left out soaking in the rain overnight on sidewalks and the proprietor of a company on the site raked in profits on the loss and even the costs of junking the goods [19].

Other than illegal gains, similar episodes reported feature a total lack of civicness precisely because fiscal damages fall on the collectivity and to these must be added damage to the environment resulting from the degradation produced by similar instances of illegal conduct.

Illegality, bribery and corruption can be ascribed as cultural indicators, more specifically as an index of the scarcity of democratic and state principles; their presence in such a massive quantity within a national community weakens the social ties, the sense of belonging to a common group and the own relationships between citizens and political institutions.

Moreover, even if they do not directly affect the majority of the population, their diffusion through the media contributes to generate a "perception" whose effects will be real, according to the famous Thomas' theorem.

In a recent study of illegality in Italy with a special look into the mechanisms of production, reproduction and the transformation of trust in regulations, Costabile and Fantozzi [20 p.24] affirmed, "present conditions in the country are perceived as worrisome especially due to a number of determined factors which can be identified as due mainly to a rare civic sense, the inadequacy of politicians and a widespread culture of illegality".

In the framework of this research, Pirzio and Marchetti [21 p.176] found that the sensation of illegality comes to the fore as the perception of the surrounding environment and a representation from above. Following on the above quoted Thomas's theorem, in this way certain effects result in spite of a premise built on sensations rather than empirical evidence: "The perception of living in a context in which certain practices are widespread or seen as such leads to the de-responsibilization of the individual, de-legitimizing conduct which respects legality".

In spite of the random potential of representations, data and estimates based on statistics arriving from the very real effects of individual conduct on a vast scale confirm the view: the extent of the now consolidated practice of the partial or non-payment of taxes, for example, while seeking private benefits to the detriment of public advantages is made clear by the annual Finance Police reports.

Other than the general figures of a shadow economy of about $20 \%$ plus a further $10 \%$ for the illegal economy for a total of some $30 \%$, the 2013 report disclosed, for example, that more than one-third of retailers do not issue receipts, that out of more than 400,000 checks carried out $32 \%$ of these showed failures to issue receipts [22].

The volume of fraud to the damage of the national and European Union budgets come to about 1.5 billion euro through practices which involve mainly false declarations of facilitated social benefits, public health surcharges, funds allocated for the support of enterprise and assistance and lines pension of financing [22 p19]. There is then a lengthy chapter on tendering public sector contracts with procedures which cost the public coffers more than 1.3 billion euro in 2013 alone.

From north to south, the ways and means for fixing tenders often show great creativity. In Brindisi, Finance Police investigators found an organization made up of businesses and local public health officials who split the take of work contracted out by eliminating the competition. In Monza the owners of a number of enterprises were able to win contracts valued at 260 million euro through bribes paid out to public officials whose duties included drawing up the technical specification for tenders. The requisites for bidders, thanks to the payoffs, were so stringent that the same enterprises always won the contracts [23].

The sphere of enterprise and these links to local administrations and national politics is not, however, the only area with a lack of a civic sense and activities aimed at benefiting the individual even in violation of the regulations. 
Corriere della Sera, one of the most ancient and prestigious Italian newspapers, has reported on the scale of jobs held down not only by workers in black or not registered but also by public servants performing two jobs who, in some cases, aggravate the conflict of interest between public sector employees and private sector professionals. Out of 1,376 checks run in this area, 1,704 workers holding down two jobs were discovered [23].

In the first two months of 2014, the Court of Auditors received reports on 104 individuals at work in the national public health sector who generated losses of 150 million euro for the system. The list included medical doctors, pharmaceutical sales representatives, patients, hospital managers and the like who passed off cosmetic plastic surgery for operations performed for serious pathologies, simulated emergency admissions to private clinics and prescriptions for enormous amounts of pharmaceutical products for subjects with no real need for them [24].

The picture which emerges is only a minimum glimpse of the phenomena of bad practices, fraud, illegal conduct perpetrated to the detriment of the general public and to the benefit of the individuals who strongly populate all the economic and occupational sectors of the country at all levels.

This cultural trait, that is to act for a personal benefit using all the methods, including illegal ones, without any regards toward the community, turns individual actions into systemic causes of failure. Coping with this type of widespread conduct in operation for a lengthy period of time, it becomes clear that the system has suffered blows as regards competitiveness, innovations and the ability to develop or react to crisis conditions.

The 2014 report on competitiveness drafted by the International Institute for Management Development ranks Italy $46^{\text {th }}$ out of the sixty nations included in the dossier compared to $40^{\text {th }}$ in 2012 [25].

Faced with these losses of resources, opportunities and wealth at the collective level, the distribution of income has become even more unequal. In $198110 \%$ of the population accounted for $26 \%$ of the nation's total wealth and by 2009 this percentage had climbed to $34 \%$ of total wealth signaling the advantages gained by a limited minority [ $26 \mathrm{p} .32]$. On the other hand, the taxation of private individuals as well as businesses has climbed to thereby favor an unequal sharing out of the burden which fuels the state machinery, that is, public services, that is, welfare. Fiscal pressure calculated by ISTAT, the National Statistics Institute, had been increased in relation to GDP from $40 \%$ in 2000 to $43.8 \%$ in 2013 .

Fiscal pressure grows up because of the growing percentage of fiscal evasion, therefore even if it is a minority of the population to elude the fiscal dues, its majority will pay - in the long term - the most relevant consequences.

From macro-economic and financial data we move on to other evidence which testifies to the spread of values, orientations and attitudes in pursuit of special, if not personal, interests. We are referring to the persistence of guilds, categories and castes in the professional fields ensuring advantages - which are rarely touched by political interventions - for those in these positions compared to the outsiders.

In this connection, Sabino Cassese wrote in 1998 of the public hand in national economic development which has been decisive not only in state interference but also through "the most varied requests for public aid" and especially requests for "the recognition of positions of privilege". The jurist refers to the "re-feudalization" of the state, to "private interests (which) are mixed in with public interests, organized into complex networks where it is difficult to distinguish between what is dictated by the state and what is instead requested by groups, categories, agencies" [28 p. 67].

More than ten years after Cassese's essay, studies of the relationships between the state and the economy result in findings which are not dissimilar. The only change seen in research conducted by Costabile and Fantozzi is the term used to describe the phenomenon, no longer re-feudalization but "neo-patrimonialism".

The definition is however more or less identical: the private and impartial use of power or, in broader terms, "those phenomena recurring more and more frequently today in the fields of politics, the economy, the professions and administrative apparatuses which involve the personal use of the goods of public and private administrations for the aim of gaining a particular advantage for those in power or in some way linked to power" [20 p. 26]

In 2002 Mauro Fotia took up the phenomena of lobbyism and the deeply fragmented structures of interests which connote Italy. The fiscal crisis of the state is not especially Italian but in this country it takes on an exceptional connotation and to understand it, according to the sociologist, one must look to the mechanism and workings of the political system which is defined by its porosity and transformation form of governance and the "shapeless and irresponsible" strengthening of democracy [28].

One of the leading causes of the crisis however can be assigned not so much to the political sphere but to the social side. According to Fotia the collective conscience, the awareness of being a part of the broader social structure and not merely a family nucleus but belonging to a group (whether friends or professional) has been subjected to a process of breakdown leading to a pluralistic phase (articulation of interests), a state of disorder and right and proper fragmentation. In this way, for example, rather than being controlled, public spending is subjected to the influence of a theory of increasingly broader interests which include not only the great industrial groups but must also take into consideration the great rentier class, construction enterprises, the aggregations of categories, organized representatives of commerce, professional groups and so on [28 p.10].

This fragmentation of the collective conscience in favor of the defense of special interests is witnessed daily: from strikes and the labor union agitation of municipal employees opposing the threat of a cut of their subsidiary salaries 
(linked to production but actually paid out like "rainfall"), and on to standoffs in such categories as taxi drivers, service station operators, lawyers and pharmacists facing liberalization.

And the attempt to defend financial and political positions attained, to preserve them from attacks from the competition, those who are excluded and pressing to get inside and take part and even colleagues attempting to grow joined to the need of political party formations for self-perpetuation set the stage for systematic disorder which, over the long run, falls back not only on those who enjoy lesser privileges (students, women, workers on short term contracts, the indigent) but the very groups holding on to their privileges.

This part has given some empirical evidence of social actions and widespread behaviors guided by the will to gain or preserve a personal or clannish advantage.

Thus, the Federal Reform case is only an example of a wider systemic loss of civicness and adherence to a normative vision of democracy that finds its evidence in both the political and social field: the only noticeable performances by Italian governments, as De Mucci [16] states, consist in the effort to demolish every policy reform passed by the previous majority, while politics, in general, seems to be more and more self-referential and dissociated from society.

In the local dimension, the federal reform has conferred to regional and municipal governments more and more decision-making powers without any counter-balancing power of control and accountability until reaching a "neo-patrimonialistic" stage of de-development. This is one of the factors which led to briberies and to the growth of corruption scandals showed in this article.

If the political system has shown a lack of accountability and responsiveness together with a decline of spirit of service towards its constituency, Italian society didn't act better, even if, in this dimension, we can find a paradoxical situation. If it's true that behind the corruption of a representative or of a civil servant there is always a private citizen as well as it's true that many professional categories do not want to give away their privileges, so as to highlight several cases of fragmentation and illegality among citizens, contrary to what previous studies affirm, these un-democratic, illegal or individualistic practices do not affect the sociological concepts of "social capital" and all the consequences that a decline of social networks can produce in terms of the political culture that "makes a democracy work".

It's not a question of "bowling alone", as Putnam [29] states, because Italian citizens still participate both in politics and in the civil society's traditional fields. Furthermore, associations play a more and more important role as agencies of mutual aid, like the scientific works of Donati explain [30], and this means that a form of solidarity exists. Moreover, this role is not only qualitative, as membership within charities or in other forms of civic engagement are in constant growth like Montanari [31 ] and Cesareo [32] point out in their studies.
So, concerning the societal dimension, it seems not to be the lack of social ties that produce the negative effects the article has described. On the contrary, it's by looking at the quality and range of these ties that the cultural factor comes to light in all its importance. While the largest associations, like parties and trade unions, are losing members, a plethora of local or small organizations rise every day, with the strong help of the web 2.0 tools.

Thus, if the social ties still exist, and if the affinity to a community is still considered a seminal value for individuals, is the "national" dimension, the sense of belonging to a national community, that is in question.

It's, more in general, a matter of widespread social trust, like some evidences show, or, using a similar concept, is a matter of collective identity, both at a national and at a supranational level.

Italian society appears resigned to pessimism about the future of Europe as well as the nation (see the data released in the 2013 Eurobarometer report), a society which believes the worst of the crisis is yet to come and, especially, one displaying scant awareness of one's own rights $(66 \%$ of the sample confirmed their ignorance of the rights associated with the concept of European citizenship).

As we have seen, this is a sharply divided society, fragmented, equipped with an extremely limited civic sense. Reports issued by the Observatory of Civil Culture in Italy provide snapshots of a social climate in which "there remain private areas occupying the preeminent positions and the bottom of the top ten must be reached to find a dimension (of solidarity) which takes the connections of the collective into account. Moreover, it must be underscored that all the options linked to a commitment (political obviously and also religious, social and environmental) are at the tail end of all the classifications from 2001 to the present" [33 p.12].

Above all, is the diffidence in interactions one with another, the Other: $80 \%$ of the people interviewed think "one can never been too careful in dealing with people", and $75 \%$ of the sample believe that if the occasion comes up, others will take advantage of one's good faith. The trust scale shows a steady decline.

So taken all together, this distrust, fragmentation of social ties (not inexistence), defense of privilege, dissemination of illegal phenomena, particularism and parochial mentality help to define and better pin down our opening hypotheses.

The reasons of these traits are to be found in the construction, diffusion and reproduction of Italian collective identity.

\section{The Italian Identity}

General examples and the specific case study paint a picture the contents which can be summarized in the title of this article. The title could be better broken down as follows: an entire collective has given ground as regards opportunities, material wealth, confidence in those above them, in enfranchising rights, guarantees, social and labor protection 
and safeguards for the fear that some of its members will lose something of these values, or someone.

As indicated, our key to interpretation lies in a cultural matrix: there are specific behavioral traits, determined values which orient the attitudes of a national collective which, when added to the effects of the general individualization process, lead to the breakup of the collective conscience, seeking refuge in particularism and the resulting crisis in the national system in its entirety. The cases examined display for us a reality dominated by special interests, the neo-patrimonial management of public resources, the relentless advance of illegal phenomena, barriers erected by entire categories in the defense of privileges and advantages, the alienation of the elderly and new socio-economic categories such as women, youth, foreigners, short-term contract workers, and the pulverization of social ties.

Read on the basis of constructivism categories [6], these phenomena can be apprehended as the effect of a cultural and symbolic order which, through the crystallization of habits, has come about to determine the repetition of schemes which "lead the way we perceive the conduct of others".

These representations play a dual role: one, precisely, captures the salient traits of the Italy; the other disseminates these traits, reiterates and transmits them to the point of transforming them into the "self-evident" reality in the common sense. Thus these traits - all the while shaping values, customs, behavior - originate with the orientation of the conduct of the collective to which they apply.

This is the reasons the led Cammelli to talk about a "gattopardesca" situation concerning the Federal Reform process: as everybody knows, one of the main sentences of "The Gattopardo" (The Leopard) - the famous Italian novel written in 1958 by Tomasi di Lampedusa - is "If we want things to stay as they are, things will have to change".

Even if referred to the Italian "Risorgimento" historical period, that is the second half of XIX century, this sentence gives a synthetic cultural overview whose effectiveness still goes on: in effect, nowadays De Mucci talks about self-referential political élites engaged in demolishing every policy reform passed by the previous majorities.

The Leopard, is a novel which gives us a representation of an historic period, but it contains also symbols, and the animal figure of the title itself is been transformed into a symbol which synthetizes the permanence of privileges thanks to an appearance of a deep and widespread change.

The dichotomy of the reality at present consists of privileges and alienation, an increasing narrow and powerful élite and the every growing masses invariably hidden away from their economic possibilities.

But this dichotomy conceals others which return us to behavioral stereotypes: the arrogant and the fool; the braggart and the victim; the clever and the tormented; the cynic and the idealist.

These modes of behaviour play a large part in Italian artistic and literary works, that is, in the mechanism of production, diffusion and reproduction of symbols which contribute to shape and to preserve a specific collective identity. How would it not be possible, for example, to recognize Don Rodrigo in the classic "I Promessi Sposi" (The Betrothed), the stereotype of the arrogant aristocratic liar plying the strength of his privileged status, ready for recourse to violence though he is afraid of his henchman Griso who would work to materially perform this violence?

There is a multitude of other examples coming from our national literary and artistic production. Returning to author Alessandro Manzoni's characters, there is Don Abbondio, the incarnation of a coward caught up in a conflict of ethics between his role as a priest and fear of the consequences of conduct which would be ethical. Then there are the characters created in Giovanni Verga's short stories, victims dominated by reverence for the forces of nature, seeking refuge in the role of divine providence and attachment to "stuff" as the material dimension of life.

This lineup of Italian stereotype representatives could be extended to the motion picture industry. "Il Sorpasso" (The Easy Life) is a 1962 film directed by Dino Risi featuring Vittorio Gassman as a braggart, an anti-conformist who belittles rules and social conventions to display, thirty years ahead of his time, generational friction which would ultimately come to the fore. Later, in the 1970s, Fantozzi, played by Paolo Villaggio, came to the screen as the incarnation of the harassed but loyal victim surrounded by his cynical colleagues who take advantage of him, laugh at and exploit him while he remains humble before the authority of his superiors.

To reach the cynic, disillusion caused by overly idealistic youth, there is the recent Italian cinema masterwork featuring the character Jep Gambardella, the protagonist of "La Grande Bellezza" (The Great Beauty).

This 2013 film provides a glimpse of the Italy of the $21^{\text {st }}$ century, a decadent society shot in a city, Rome, in which the sole traits of sublime splendor emanate from the past, the imperial and republican ruins, the residences of the capital's aristocracy. A society described through the cynical and ruthless glance of a man on the verge of old age. A world in which a sense of resignation, ennui, stopped up by the effect of the diversions in flights into evasion and amusements, parties, dinners and artistic performances, predominate.

Representations of the present social stratification can be perceived even in the spacial arrangements of the scenes. A penthouse serves as the setting for an anomic routine in which members of a restricted élite gather, journalists, entrepreneurs, politicians and priests representing the privileged. Lower down, spatially and metaphorically, is the ant hill of the people, the motor vehicle traffic of those who wearily lead their lives. Standing out above, in the latest construction of materials and symbols, is the residence of a character as mysterious as he is discreet, a representative of the sphere of finance, the corrupted or the corrupter. The character is arrested and is proud of what he does and of himself at the same time, so much so that he categorizes himself neither as "the Italy which works, which produces."

From an historic point of view, these characteristics find 
confirmation in the political and institutional scale of fragmentation of the Italian peninsula. This fragmentation began with the fall of the Roman Empire and was continued with the rise of city state realities which, on the one hand, contributed to the birth and strengthening of the spirit of mercantilism and proto-capitalism and, on the other, impeded the development of a sense of belonging linked to a collective dimension on a national scale as opposed to what occurred in England and France. This parochialism is strengthened thanks to the special relationship between Italians and authority as perceived in relations of patronage and exploitation of these relations. In many cases, these relations are seen as linked more to a status of a subject rather than that of a citizen.

The own "double morality", shown by representatives and described in the federal reform case study, finds its historical explanation in the contemporary presence of a "double authority" which had to be respected [3]: on one hand, the Prince; on the other hand, the spiritual power represented by the Pope. Later, after the national building process, this double authority has turn into State and religious order.

The collective stalemate as regards civic, political and economic matters has today reached its highest level and can be shared in a summary of the words of Revelli [34] for describing numerous cases of social malaise in Italy: "They talk all together, but each for oneself, of perverse solitude which is never declared in the uproar in the aisle of a supermarket; of a defeat exchanged, too often due to occasion and opportunity (...), they are radical losers, deluded by having won (...) they are the anthropological-cultural translation of the Italy which has fallen, deluding itself that thinking it has grown".

\section{REFERENCES}

[1] Montanari A. Eroi immaginari. L’identità nazionale nei romanzi, film, telefilm e polizieschi. Napoli: Liguori; 1995.

[2] Hobsbawn EJ, Ranger T. L'invenzione della tradizione. Torino: Einaudi; 1987.

[3] Montanari A. Stereotipi nazionali: modelli di comportamento e relazioni in Europa. Napoli: Liguori; 2002.

[4] Santambrogio A. Il senso comune. Bari: Laterza; 2006.

[5] Gallino L. Dizionario di Sociologia. Milano: TEA; 1993.

[6] Berger PL, Luckman T. The Social Construction of Reality. New York: Doubeday \& Co.; 1966.

[7] Lijphart A. The Politics of Accommodation. Berkeley: University of California Press; 1968.

[8] Lijphart A. Democracy in Plural Societies: A Comparative Exploration. New Haven: Yale University Press; 1977.

[9] Crozier P. The Bureaucratic Phenomenon, Chicago: Chicago University Press; 1964.

[10] Goblot E. La barrière et le niveau. Etude sociologique sur la bourgeoisie française modern. Presses universitaires de France; 2010.
[11] Antonini L. Federalismo all'italiana. Roma: Marsilio; 2013.

[12] Montanari A. Identità allo specchio. Destra e sinistra in Italia. Soveria Manelli: Rubbettino; 2010.

[13] Cammelli M. Federalismo fiscale fra i gattopardi. Il Mulino. 2010; 1:21-31.

[14] Corte dei Conti. Relazione sullo stato della giustizia nell'anno 2012. 2013.

[15] Pizzetti F. A dieci anni dalla riforma del titolo V: perché il federalismo in Italia. Le Regioni. 2011 a. XXXVIII; 5: 1013-20.

[16] De Mucci R. Democrazia Dissociativa. Soveria Manelli: Rubettino. 2013.

[17] Borrelli M: "Le Monde praises Renzi: a dream of an Italian Renaissance". Termometro Politico (Internet). 2014 June 20; Available from:

http://www.termometropolitico.it/124914_monde-esalta-renz i-sogno-rinascimento-italiano.html

[18] Luca Zaia, Interview given to the daily Il Gazzettino. 2014 June 17.

[19] Trash and mattresses abandoned on the road. This is the Torpignattara dump. Il Messaggero 2014 June 24.

[20] Costabile A, Fantozzi P, editors. Legalità in crisi. Il rispetto delle regole in politica e economia. Roma: Carocci; 2013.

[21] Marchetti C, Pirzio Ammassari G. Mercato e istituzioni politiche nella rappresentazione della legalità. In: Costabile A, Fantozzi P, editors. Legalità in crisi. Roma: Carocci; 2013. pp. 153-78.

[22] Finance Police. Annual Report. 2013.

[23] Sarzanini F. From university professor to public manager. Fraud of two jobs off the record. Corriere della Sera. 2014 Jen 26.

[24] Record Swindle and Public Health Fraud. The Charge of False Exemption. Corrirere della Sera. 2014 April 14.

[25] IMD. World Competitiveness Yearbook. 2014.

[26] Acciari P, Mosetti S. A map of inequality of wealth in Italy. Rome: Bank of Italy Press; 2013.

[27] Cassese S. Lo Stato Introvabile. Roma: Donzelli; 1998.

[28] Fotia M. Le lobby in Italia. Gruppi di pressione e potere. Roma: Dedalo; 1997.

[29] Putnam R. Bowling Alone: The Collapse and Revival of American Community. Simon \& Schuster: Touchstone. 2001.

[30] Donati P. La società civile in Italia. Milano: Mondadori; 1997.

[31] Montanari A. In Libera uscita. Roma: Carocci; 2011.

[32] Cesareo V. I protagonisti della società civile. Soveria Mannelli: Rubettino; 2003.

[33] Osservatorio sulla Cultura Civica in Italia: 2001-2007. Available from:

http://www.comieco.org/pubblicazioni/pubblicazioni-comiec o/news/osservatorio-sulla-cultura-civica-in-italia-_313141.as $\mathrm{px}$

[34] Revelli M. Poveri, noi. Torino: Einaudi; 2010. 